\title{
Preliminary evaluation of gellan gum as mud thickener
}

\author{
Chang Hong Gao ${ }^{1}$
}

Received: 3 March 2015/Accepted: 13 December 2015/Published online: 30 December 2015

(c) The Author(s) 2015. This article is published with open access at Springerlink.com

\begin{abstract}
Gellan gum (GLG) is a biopolymer widely used in food industry. This paper investigates the potential of high acyl GLG as additive for drilling mud. The impacts of temperature, sodium, potassium and calcium ions on mud properties were tested. Experiments show that GLG is able to effectively increase viscosity of drilling mud, but has no significant effect on filtrate loss. Gellan gum, in a unique way, boosts mud viscosity more effectively at elevated temperature. Low concentrations of sodium and potassium ions cause mud viscosity to escalate, but mud properties stabilize at high concentrations of monovalent ions. On the other hand, calcium ion depresses mud viscosity and yield point. This study demonstrates that GLG has the potential to be employed as mud thickener in drilling operations.
\end{abstract}

Keywords Gellan gum · Drilling mud · Viscosity · Rheology

\section{Introduction}

Drilling mud plays a vital role in successful petroleum drilling operations. Mud must maintain good viscosity to effectively suspend and transport cuttings. Mud should also have a low filtrate loss to minimize formation damage and well sloughing. Traditionally, carboxymethyl cellulose (CMC) and hydroxyethyl cellulose (HEC) were widely

Chang Hong Gao

237184689@QQ.com

1 Sinopec Shengli E\&P Research Institute, Dongying 257000, Shandong, China adopted as mud thickener (Rabia 1985). At the meantime, the industry has been seeking next-generation mud additives to meet new challenges in drilling operations.

Gellan gum (GLG) is a polysaccharide produced by fermentation of a pure culture of Sphingomonas elodea. The polymer is a linear anionic heteropolysaccharide composed of tetrasaccharide repeating unit consisting of two $\beta$-D-glucose, one $\beta$-D-glucuronic acid and one $\alpha$-Lrhamnose residues (Grasdalen and Smidsrod 1987). Gellan gum is available in two forms: high and low acyl content. Their structures are presented in Fig. 1 (Kelco 2007). Gellan gum has been approved by FDA to be used as a safe food additive. For example, GLG improves the texture of ice cream, milk, cookies, juices and jellies (Kelco 2007).

Previously, many researchers studied the behavior of low acyl GLG (Miyoshi et al. 1994, 1996; Nitta and Nishinari 2005; Gohel et al. 2009). According to their studies, low acyl GLG produces firm and brittle gels at elevated temperature, whereas the high acyl GLG forms soft and elastic gels. Varying the ratios of the two forms of gellan produces a wide variety of textures (Gohel et al. 2009). The mechanism of gel formation is beyond the scope of this paper and can be found in literature (Grasdalen and Smidsrod 1987).

Unfortunately, the research on high acyl GLG is very limited. The potential applications of GLG in the petroleum industry have not yet been investigated. The high acyl GLG produces viscous fluid; therefore, it may be a potential candidate as mud thickener. This paper is focused on the rheological behavior of drilling mud containing high acyl GLG. The influences of temperature, monovalent and divalent ions on mud properties are also assessed. In brief, the author attempts to evaluate the potential of GLG as mud additive. 


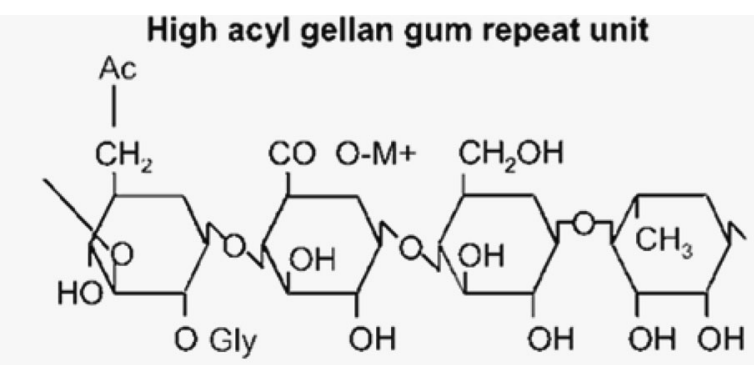

Low acyl gellan gum repeat unit

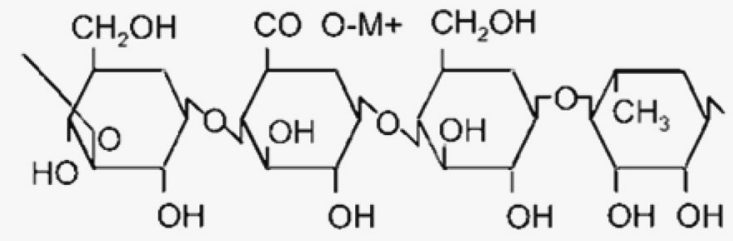

$\mathrm{Ac}=$ acetate group

Gly = glycerate group

Fig. 1 Molecular structure of gellan gum (GLG)

\section{Materials and methods}

The high acyl GLG sample was provided by Tianwei chemical company in China. Other chemicals, including sodium chloride, potassium chloride, calcium chloride, $\mathrm{CMC}$, and bentonite clay, were purchased from local suppliers. Mud samples were prepared with high-speed mixer. Rheology tests were conducted with OFITE 8-speed mud viscometer. Filtrate tests were conducted on OFITE standard filter press. Mud testing followed standard laboratory procedures (Gao 2015).

The first step was to prepare base mud. The base mud was made by mixing $50 \mathrm{~g}$ bentonite clay into $1 \mathrm{~L}$ tap water. According to a report (Kelco 2007), the aqueous solution of high acyl GLG forms thermally reversible gel. Therefore, the second test was designed to investigate the effect of temperature on GLg mud. Mud containing GLG was heated to $70{ }^{\circ} \mathrm{C}$, then cooled down to room temperature $\left(25^{\circ} \mathrm{C}\right)$, and heated up again. The mud viscosity data during this process were recorded.
Third, GLG was added to base mud at varied dosages to evaluate the effect of GLG concentration on mud properties. Fourth, salts $\left(\mathrm{NaCl}, \mathrm{KCl}\right.$, and $\left.\mathrm{CaCl}_{2}\right)$ were added to GLG mud to assess the effect of monovalent ions and divalent ions on mud properties. Finally, a filtrate test was conducted on GLG mud. The test matrix is given in Table 1 .

\section{Results and discussions}

Figure 2 compares the mud viscosity before and after heating. For the black curve labeled base mud, the test mud contained water and clay only. For the blue curve labeled GLG mud before heating, $1 \mathrm{~g} / \mathrm{L}$ GLG was mixed into base mud at room temperature, and viscosity was measured (i.e. without heating). For the red curve labeled GLG mud after heating, mud containing GLG was first heated to $70{ }^{\circ} \mathrm{C}$, then cooled to $25{ }^{\circ} \mathrm{C}$. And mud viscosity was measured at $25{ }^{\circ} \mathrm{C}$.

As shown in Fig. 2, mud viscosity increased immediately after addition of GLG. Moreover, mud viscosity increased significantly after heating. For example, at moderate shear rate $(50 / \mathrm{s})$, the base mud demonstrated a viscosity of $42 \mathrm{cP}$. After adding GLG, mud viscosity increased to $71 \mathrm{cP}$. After heating, mud viscosity jumped to $240 \mathrm{cP}$. This phenomenon agrees with previous finding: GLG forms soft gel at elevated temperature (Kelco 2007).

Compared with CMC, GLG is more effective in boosting mud viscosity (see the green curve in Fig. 2). Figure 2 also shows that mud viscosity is high at low shear rate, which is beneficial for suspending and transporting cuttings. At high shear rate, mud viscosity reduces, which also reduces the pressure loss in the mud circulation system.

Figure 3 further explains the effects of heating on mud viscosity. Without heating, both mud samples showed very similar viscosity at room temperature, despite different concentrations of GLG. After heating, both mud samples became much more viscous, while the mud with higher GLG concentration demonstrated higher viscosity.

Table 1 Summary of test matrix

\begin{tabular}{lllll}
\hline Test no. & Objective of test & Temperature $\left({ }^{\circ} \mathrm{C}\right)$ & $\begin{array}{l}\text { Gellan gum } \\
\text { concentration }(\mathrm{g} / \mathrm{L})\end{array}$ & $\begin{array}{l}\text { Salt concentration } \\
(\mathrm{g} / \mathrm{L})\end{array}$ \\
\hline 1 & Prepare base mud & 25 & 0 & 0 \\
2 & Study effect of temperature & $25-70$ & 1 & 0 \\
3 & Study effect of $\mathrm{GLG}$ concentration & 25 & $0.5,1$ & 0 \\
4 & Study effect of $\mathrm{NaCl}$ & 25 & 1 & $2-100(\mathrm{NaCl})$ \\
5 & Study effect of $\mathrm{KCl}$ & 25 & 1 & $2-50(\mathrm{KCl})$ \\
6 & Study effect of $\mathrm{CaCl}{ }_{2}$ & 25 & 1 & $2-30(\mathrm{CaCl} 2)$ \\
7 & Measure filtrate loss & 25 & 1 & 0 \\
\hline
\end{tabular}




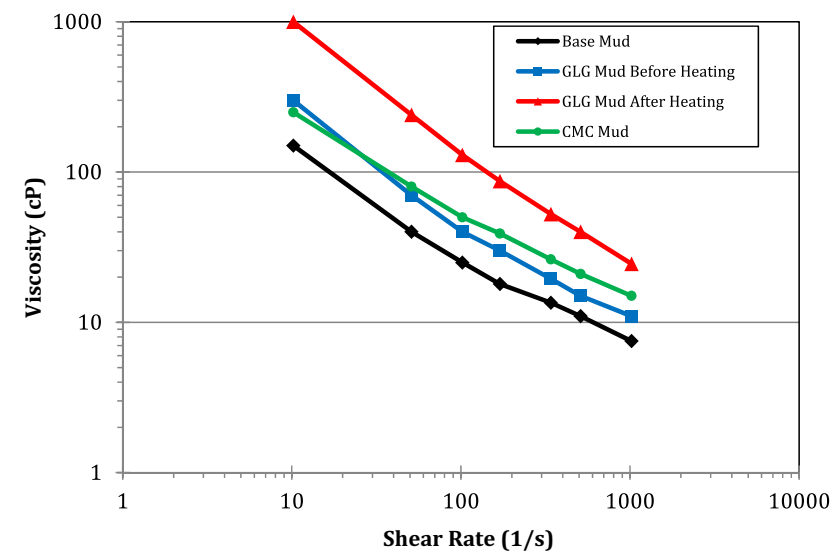

Fig. 2 Effect of heating on GLG mud viscosity

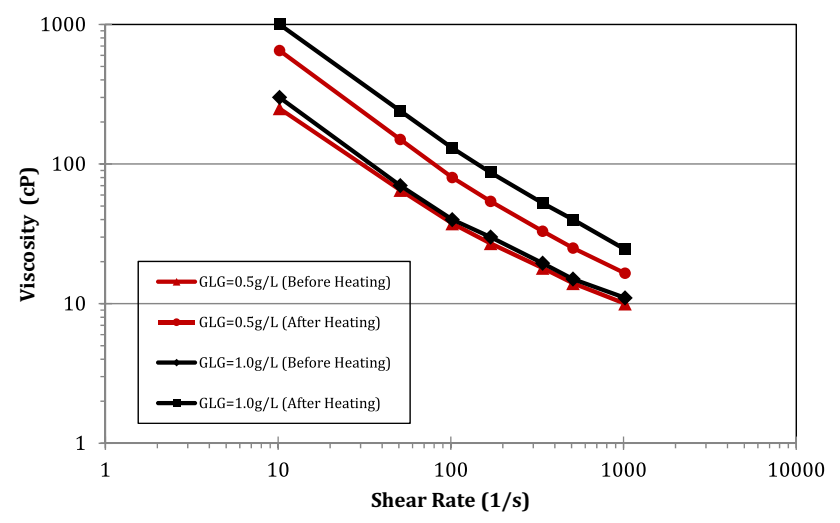

Fig. 3 Comparison of mud viscosity before and after heating

After the initial heating and cooling process, the GLG mud was again heated up and the mud properties were recorded. Figure 4 presents the mud properties when temperature increased, including apparent viscosity (AV), plastic viscosity (PV) and yield point (YP). Tests show that PV continued to decline when temperature increased, while $\mathrm{AV}$ and YP first dropped then recovered at elevated temperature. Reasonably high viscosity and yield point are beneficial for transportation of cuttings.

Mud viscosity data at varied shear rates and varied temperatures are presented in Fig. 5. GLG mud viscosity first declined, but recovered at higher temperature. This reveals that viscosity of GLG mud is thermally reversible, and GLG mud demonstrates good stability under high temperature.

While drilling through anhydrite, gypsum, and high salinity zones, salt contaminations may occur and cause detrimental impacts on mud properties. For instance, sodium and calcium ions are major contaminants to freshwater-based mud systems. These ions tend to replace the sodium ions on the clay surface through a base exchange, thus causing undesirable changes in mud

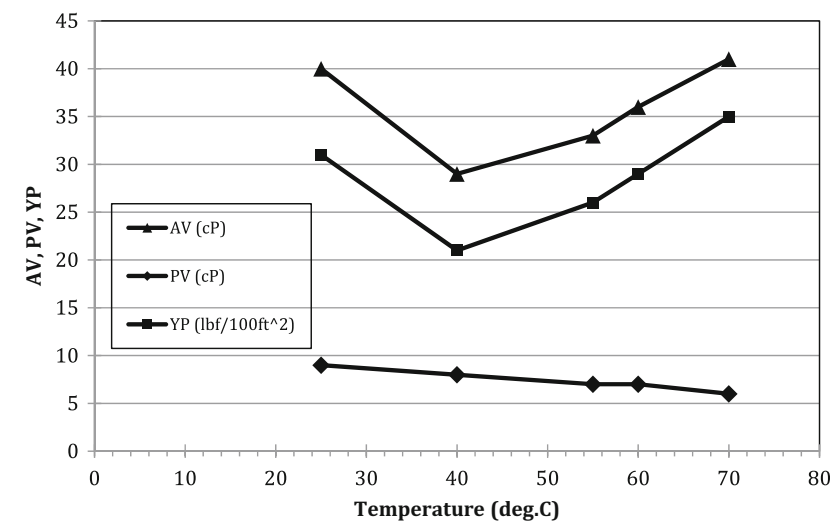

Fig. 4 Effect of temperature on GLG mud properties

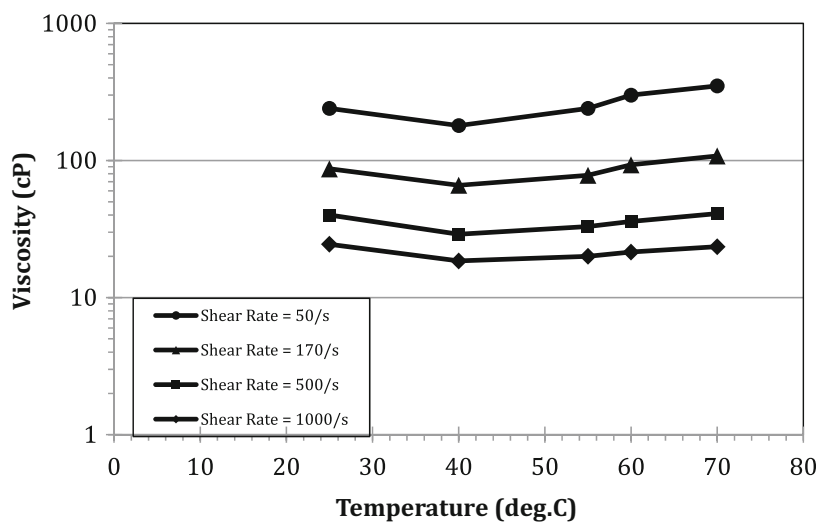

Fig. 5 Viscosity of GLG mud at elevated temperatures and shear rates

properties such as rheology and filtration (Chen et al. 2014). It also causes added thinners to the mud system to become ineffective. It is therefore important to test the mud's reaction to these ions.

Figure 6 shows mud properties after addition of sodium chloride. At low sodium concentrations, both mud AV and YP escalated. When sodium concentration exceeded $10 \mathrm{~g} / \mathrm{L}$, mud properties became relatively stable. Even at very high sodium concentration (100 g/L), GLG mud maintained its viscosity similar to its original viscosity.

The influences of potassium chloride on mud properties are presented in Fig. 7. Compared with $\mathrm{NaCl}$, potassium has more significant impacts on mud parameters. Both mud $\mathrm{AV}$ and YP escalated upon addition of potassium, and both parameters peaked when the $\mathrm{KCl}$ concentration reached 10-20 g/L. After $\mathrm{KCl}$ reached $25 \mathrm{~g} / \mathrm{L}$, mud $\mathrm{AV}$ and YP started to decline and stabilize. At the early stage of sodium and potassium attacks, mud thinners may be required to battle the abrupt increase in mud viscosity.

Influence of calcium on mud properties is shown in Fig. 8. Calcium caused all three key parameters to decline. While calcium chloride reached $30 \mathrm{~g} / \mathrm{L}$, mud AV dropped 


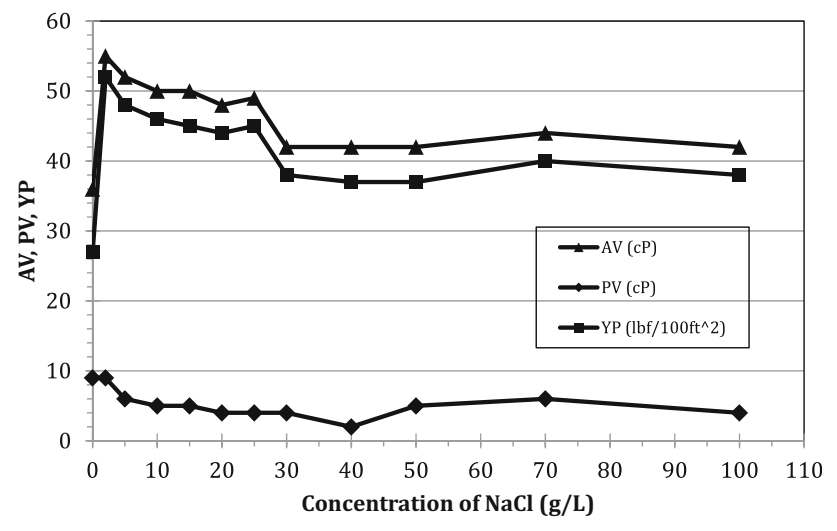

Fig. 6 Mud properties under influence of sodium chloride

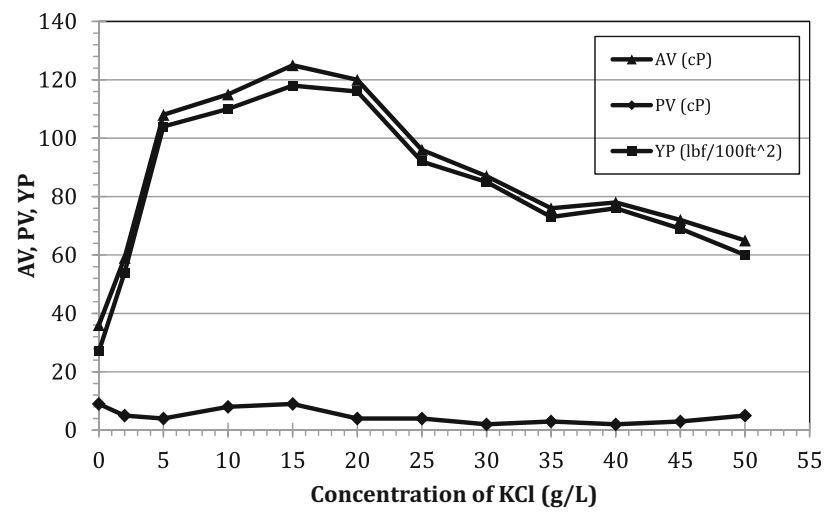

Fig. 7 Mud properties under influence of potassium chloride

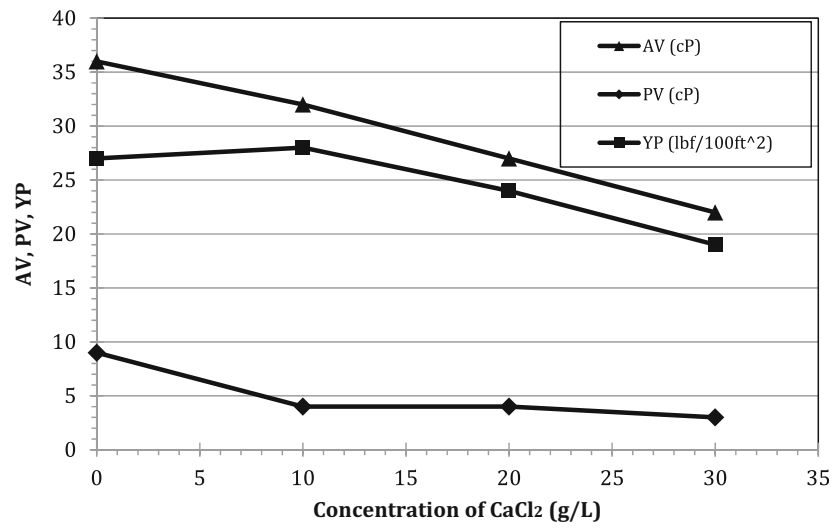

Fig. 8 Influence of calcium chloride on mud properties

from 36 to $22 \mathrm{cP}$. As long as the concentration of calcium is not too high, mud properties are still within control.

For all the tests in Figs. 4, 5, 6, 7 and 8, concentration of GLG in mud samples was maintained at $1 \mathrm{~g} / \mathrm{L}$. Mud samples were prepared by mixing GLG into base mud. Afterward, mud samples were heated to $70{ }^{\circ} \mathrm{C}$, then cooled down to room temperature. Salts were then added and measurements were conducted at room temperature. Based
Table 2 Prices of mud chemicals

\begin{tabular}{lll}
\hline $\begin{array}{l}\text { Product } \\
\text { name }\end{array}$ & $\begin{array}{l}\text { Price per thousand } \\
\mathrm{kg}(\mathrm{CNY})\end{array}$ & $\begin{array}{l}\text { Price per thousand } \\
\mathrm{kg}(\mathrm{USD})\end{array}$ \\
\hline Gellan gum & 12,500 & 1953 \\
CMC & 8000 & 1250 \\
PAM & 10,000 & 1560 \\
\hline
\end{tabular}

on the test results, a dosage of $1 \mathrm{~g} / \mathrm{L}$ is recommended for field application.

At the end of tests, mud samples containing GLG and salts were heated to $80{ }^{\circ} \mathrm{C}$ for $6 \mathrm{~h}$, and the mud properties were measured. It was observed that mud properties remained very stable at $80{ }^{\circ} \mathrm{C}$. It can be concluded that GLG mud is stable at moderately high temperature. Filtrate tests were also conducted on base mud and GLG mud. Base mud produced $8.5 \mathrm{~mL}$ filtrate in $7.5 \mathrm{~min}$, while the GLG mud generated $8 \mathrm{~mL}$ filtrate for the same duration. Gellan gum has no significant effect on filtrate control.

Table 2 gives the prices of GLG and common mud chemicals in Chinese and US currency. It is obvious that GLG is more expensive than CMC and PAM (Polyacrylamide). However, the price gap is not significant. On the other hand, GLG is a more effective thickener. As a biopolymer, GLG causes less damage to environment than artificially synthesized chemicals.

\section{Conclusions}

(1) High acyl GLG is very effective at boosting mud viscosity, especially at high temperature. (2) Sodium and potassium ions have significant impacts on GLG mud properties. (3) Mud containing GLG shows good stability at relatively high temperature. (4) GLG is not effective in reducing filtrate loss.

Acknowledgement The author is grateful for the fund provided by Shandong province through Taishan scholar program.

Open Access This article is distributed under the terms of the Creative Commons Attribution 4.0 International License (http:// creativecommons.org/licenses/by/4.0/), which permits unrestricted use, distribution, and reproduction in any medium, provided you give appropriate credit to the original author(s) and the source, provide a link to the Creative Commons license, and indicate if changes were made.

\section{References}

Chen X, Fan H, Guo B, Gao D (2014) Real-time prediction and optimization of drilling performance based on a new mechanical specific energy model. Arab J Sci Eng 39(11):8221-8231 
Gao H (2015) Potential of welan gum as mud thickener. J Pet Explor Prod Technol. doi:10.1007/s13202-014-0114-1

Gohel M, Parikh R, Nagori S (2009) Preparation and evaluation of soft gellan gum gel. Indian J Pharm Sci 71(2):120-124. doi:10. 4103/0250-474X.54273

Grasdalen H, Smidsrod O (1987) Gelation of gellan gum, carbohydrate polymers. Carbohydr Polym 7(5):371-393. doi:10.1016/ 0144-8617(87)90004-X

Kelco (2007) Gellan gum, 5th edn. Available via www.cpkelco.com

Miyoshi E, Takaya T, Nishinari K (1994) Gel-sol transition in gellan gum solutions: rheological studies on the effects of salts. Food Hydrocoll. 8(6):505-527
Miyoshi E, Takaya T, Nishinari K (1996) Rheological and thermal studies of gel-sol transition in gellan gum aqueous solutions. Carbohydr Polym 30(2):109-119

Nitta Y, Nishinari K (2005) Gelation and gel properties of polysaccharides gellan gum. J Biol Macromol. 5(3):47-52

Rabia H (1985) Oilwell drilling engineering. Graham and Trotman Ltd $105-130$ 